\title{
SISTEM PAKAR MENENTUKAN KARAKTERISTIK DAN BAKAT SISWA DENGAN MENGGUNAKAN METODE FORWARD CHAINING
}

\author{
Rizka Tri Alinse \\ Program Studi Teknik Informatika Fakultas Ilmu Komputer Universitas Dehasen Bengkulu \\ Jalan Meranti Raya No.32 Kelurahan Sawah Lebar Kota Bengkulu Telp. 22027 Fax. (0736) 341139 \\ rizkatri07@gmail.com
}

\begin{abstract}
Abstrak: Sekolah Luar Biasa (SLB) Negeri Kota Bengkulu merupakan institusi pendidikan yang memiliki beragam siswa dari berbagai latar belakang keluarga yang berbeda, setiap siswa memiliki karakter yang berbeda dengan siswa yang lain, untuk itu perlu pendekatan khusus untuk masing-masing siswa. Untuk memahami setiap karakter masing-masing siswa maka diperlukan aplikasi sistem pakar untuk membantu menentukan karakter yang ada serta bakat yang dimiliki setiap siswa, agar dapat memudahkan guru dalam memberikan pelayanan pengajaran yang sesuai dengan karakter masing-masing siswa yang ada. Tujuan penelitian ini adalah Membuat sistem pakar untuk menentukan karakteristik dan bakat siswa menggunakan Visual Basic 6.0 di SLB Negeri (Autis Center) Kota Bengkulu. Penelitian dilakukan di SLB Negeri Kota Bengkulu pada tanggal 16 s.d 28 Maret 2015. Pada penelitian ini pengumpulan data dilakukan dengan menggunakan metode observasi dan studi pustaka. Dari hasil penelitian ini menunjukkan bahwa dengan adanya sistem pakar menentukan karakteristik dan bakat siswa, dapat membantu guru dalam mengenali karakter setiap siswa dan mengetahui jika ada siswa yang memiliki bakat.
\end{abstract}

Kata Kunci: Sistem Pakar, Karakter, Bakat

\begin{abstract}
Extraordinary School Bengkulu City an educational institution that has a variety of students from different family backgrounds, each student has a different character with the other students, for it needs a special approach to each student. To understand every character of each student will require the application of expert system to help determine the existing character and talents of each student, in order to facilitate teachers in providing teaching services in accordance with the character of each student there. The purpose of this study is build an expert system to determine the characteristics and talents of students using Visual Basic 6.0 in SLBN (Autism Center) Bengkulu City. The study was conducted in Bengkulu City State SLB on 16 to March 28, 2015. In this research, data collection is done by using the method of observation and literature. From the results of this study indicate that the presence of an expert system to determine the characteristics and talents of students, can help teachers recognize
\end{abstract}

the character of each student and determine if there are students who have a talent.

Keywords: Expert System, characteristics, Talents

\section{PENDAHULUAN}

Perkembangan ilmu pengetahuan dan teknologi sangat dipengaruhi oleh globalisasi yang membawa perubahan positif dalam berbagai bidang kehidupan bermasyarakat, perkembangan itu adalah ilmu pengetahuan dan teknologi dalam bentuk perkembangan komputer yang awalnya digunakan sebagai alat hitung saja, tetapi juga sebagai alat untuk membantu menyelesaikan masalah serta dapat menampilkan berbagai informasi dalam pengolahan data secara otomatis. 
Jurnal Pseudocode, Volume V Nomor 1, Februari 2018, ISSN 2355-5920

www.ejournal.unib.ac.id/index.php/pseudocode

Contoh bidang lain pengembangan kecerdasan buatan adalah sistem pakar yang menggabungkan pengetahuan dan penelusuran data untuk memecahkan masalah yang secara normal memerlukan keahlian manusia. Tujuan pengembangan sistem pakar sebenarnya bukan untuk menggantikan peran manusia, akan tetapi untuk mensubtitusikan pengetahuan manusia ke dalam bentuk sistem, sehingga dapat digunakan oleh orang banyak

Sekolah Luar Biasa (SLB) Negeri Kota Bengkulu merupakan institusi pendidikan yang memiliki beragam siswa dari berbagai latar belakang keluarga yang berbeda, setiap siswa memiliki karakter yang berbeda dengan siswa yang lain, untuk itu perlu pendekatan khusus untuk masing-masing siswa. Untuk memahami setiap karakter masing-masing siswa maka diperlukan aplikasi sistem pakar untuk membantu menentukan karakter yang ada serta bakat yang dimiliki setiap siswa, agar dapat memudahkan guru dalam memberikan pelayanan pengajaran yang sesuai dengan karakter masing-masing siswa yang ada.

\section{LANDASAN TEORI}

\section{A. Sistem Pakar}

Sistem pakar adalah sistem yang menggabungkan pengetahuan dan penelusuran data untuk memecahkan masalah yang normal memerlukan keahlian manusia. Tujuan pengembangan sistem pakar sebenarnya bukan untuk menggantikan peran manusia, tetapi untuk mensubtitusikan pengetahuan manusia ke dalam bentuk sistem, sehingga dapat diperoleh oleh orang banyak [1].

Perbandingan antara kemampuan sistem pakar manusia dan sistem komputer yang menjadi pertimbangan pengembangan sistem pakar:
Tabel 1. Perbandingan Sistem Pakar dan Komputer

\begin{tabular}{|l|l|}
\hline \multicolumn{1}{|c|}{ Pakar Manusia } & \multicolumn{1}{c|}{ Sistem Pakar } \\
\hline $\begin{array}{l}\text { Terbatas waktu karena } \\
\text { manusia membutuhkan } \\
\text { istirahat. Membutuh kan } \\
\text { istirahat. }\end{array}$ & $\begin{array}{l}\text { Tidak terbatas karena } \\
\text { dapat digunakan kapan pun } \\
\text { juga.digunakan kapan pun } \\
\text { juga. }\end{array}$ \\
\hline $\begin{array}{l}\text { Tempat akses bersifat lokal } \\
\text { pada suatu tempat saja } \\
\text { dimana pakar berada. }\end{array}$ & $\begin{array}{l}\text { Dapat digunakan di } \\
\text { berbagai tempat. }\end{array}$ \\
\hline $\begin{array}{l}\text { Pengetahuan bersifat } \\
\text { variabel dan dapat berubah- } \\
\text { ubah tergantung situasi. }\end{array}$ & $\begin{array}{l}\text { Pengetahuan bersifat } \\
\text { konsisten. }\end{array}$ \\
\hline $\begin{array}{l}\text { Kecepatan untuk } \\
\text { menemukan solusi sifatnya } \\
\text { bervariasi. }\end{array}$ & $\begin{array}{l}\text { Kecepatan untuk } \\
\text { memberikan solusi } \\
\text { konsisten dan lebih cepat } \\
\text { daripada manusia. }\end{array}$ \\
\hline $\begin{array}{l}\text { Biaya yang harus dibayar } \\
\text { untuk konsultasi biayanya } \\
\text { sangat mahal. }\end{array}$ & $\begin{array}{l}\text { Biaya yang dikeluarkan } \\
\text { lebih murah. }\end{array}$ \\
\hline
\end{tabular}

Selain banyak manfaat yang diperoleh, ada juga kelemahan pengembangan sistem pakar, yaitu:

1. Daya kerja dan produktivitas manusia menjadi berkurang karena semuanya dilakukan secara otomatis oleh sistem.

2. Pengembangan perangkat lunak sistem pakar lebih sulit dibandingkan pernagkat lunak konvensional. Hal ini dapat dilihat dari tabel perbandingan berikut:

Tabel 2. Perbandingan perangkat lunak konvensional dan perangkat lunak sistem pakar

\begin{tabular}{|l|l|}
\hline \multicolumn{1}{|c|}{$\begin{array}{c}\text { Perangkat lunak } \\
\text { konvensional }\end{array}$} & $\begin{array}{c}\text { Perangkat lunak sistem } \\
\text { pakar }\end{array}$ \\
\hline Fokus pada solusi & Fokus pada permasalahan. \\
\hline $\begin{array}{l}\text { Pengembangan dapat } \\
\text { dilakukan secar individu }\end{array}$ & $\begin{array}{l}\text { Pengembangan dilakukan } \\
\text { oleh tim } \\
\text { kerja }\end{array}$ \\
\hline $\begin{array}{l}\text { Pengembangan secara } \\
\text { sekuensial }\end{array}$ & $\begin{array}{l}\text { Pengembangan secara } \\
\text { iteratif. }\end{array}$ \\
\hline
\end{tabular}

\section{B. Karakteristik}

Pada buku pendidikan karakter usia dini [2] memandang karakter mengacu kepada serangkaian sikap (attitudes), perilaku (behaviors), motivasi (motivation), dan keterampilan (skills). Karakter 
sebenarnya berasal dari bahasa Yunani yang berarti "to mark" atau menandai, dan memfokuskan bagaimana mengaplikasikan nilai kebaikan itu dalam bentuk tindakan atau tingkah laku.

Karakter adalah watak, tabiat, akhlak, atau kepribadian seseorang yang terbentuk dari hasil internalisasi berbagai kebajikan (virtues) yang diyakini dan digunakan sebagai landasan untuk cara pandang, berpikir, bersikap, dan bertindak.

\section{Bakat}

Menurut Sukmadinata [3] Bakat atau aptitude merupakan kecakapan potensial yang bersifat khusus, yaitu khusus dalam sesuatu bidang atau kemampuan tertentu. Bakat (aptitude) mengandung makna kemampuan bawaan yang merupakan potensi (potential ability) yang masih perlu dikembangan atau dilatih agar dapat terwujud. Bakat berbeda dengan kemampuan (ability) yang mengandung makna sebagai daya untuk melakukan sesuatu, sebagai hasil dari pembawaan dan latihan. Bakat juga berbada dengan kapasitas (capacity) dengan sinonimnya, yaitu kemampuan yang dapat dikembangkan di masa yang akan datang apabila latihan dilakukan secara optimal.

Bakat adalah kemampuan alamiah untuk memperoleh pengetahuan dan keterampilan, baik yang bersifat umum maupun yang bersifat khusus.Bakat umum apabila kemampuan yang berupa potensi tersebut bersifat umum. Misalnya bakat intelektual secara umum, sedangkan bakat khusus apabila kemampuan bersifat khusus. Misalnya bakat akademik, sosial, dan seni kinestetik. Bakat khusus biasanya disebut talent sedangkan bakat umum (intelektual) biasanya disebut gifted [4].

\section{Faktor-faktor yang mendukung}

Faktor-faktor yang mendukung untuk mengembangkan karakteristik dan bakat siswa [5].

\section{Faktor Intern}

\section{a. Faktor Bawaan (Genetik)}

Faktor ini merupakan faktor yang mendukung perkembangan individu dalam bakat sebagai totalitas karakteristik individu yang diwariskan orang tua kepada anak dalam segala potensi melalui fisik maupun psikis yang dimiliki individu sebagai pewarisan dari orang tuanya. Faktor hereditas sebagai faktor pertama munculnya bakat. Dari segi biologi, bakat sangat berhubungan dengan fungsi otak. Bila otak kiri dominan, segala tindakan dan verbal, intelektual, sequensial, teratur rapi, dan logis Sedangkan otak kanan berhubungan dengan masalah spasial, non verbal, estetik dan artistic serta atletis.

\section{b. Faktor kepribadian}

Faktor kepribadian yaitu keadaan psikologis dimana perkembangan potensi anak tergantung pada diri dan emosi anak itu sendiri. Hal ini akan membantu anak dalam membentuk konsep serta optimis dan percaya diri dalam mengembangkan bakatnya.

\section{Faktor Extern}

\section{a. Faktor lingkungan}

Faktor lingkungan merupakan olahan dari berbagai hal untuk mendukung pengembangan minat dan bakat anak.

Ada sejumlah faktor yang mempengaruhi perkembangan bakat khusus yang secara garis besar dikelompokkan menjadi faktor internal dan eksternal. Faktor internal adalah faktor yang berasal dari dalam diri individu. Faktor-faktor internal tersebut adalah: 
1. Minat

2. Motif berprestasi

3. Keberanian mengambil risiko

4. Keuletean dalam menghadapi tantangan

5. Kegigihan atau daya juang dalam mengatasi kesulitan yang timbul

Karakteristik yang berkaitan dengan perkembangan faktor biologis cenderung lebih bersifat tetap, sedangkan karakteristik yang berkaitan dengan faktor psikologis lebih mudah berubah karena dipengaruhi oleh pengalaman dan lingkungan.

Karakter seseorang baik disengaja atau tidak, didapatkan dari orang lain yang sering berada didekatnya atau yang sering mempengaruhinya, kemudian ia mulai meniru untuk melakukannya. Oleh karena itu, seorang anak yang masih polos seringkali akan mengikuti tingkah laku orang tuanya atau teman mainnya, bahkan pengasuhnya. Erat kaitan dengan masalah ini, seorang psikolog berpendapat bahwa karakter berbeda dengan kepribadian, karena kepribadian merupakan sifat yang dibawa sejak lahir dengan kata lain kepribadian bersifat genetis.

\section{E. Mekanisme Inferensi}

Makanisme inferensi adalah bagian dari sistem pakar yang melakukan penalaran dengan menggunakan isi daftar aturan berdasarkan urutan dan pola tertentu. Selama proses konsultasi antar sistem dan pemakai, mekanisme inferensi menguji aturan satu demi satu sampai kondisi itu benar.

Secara umum ada dua teknik utama yang digunakan dalam mekanisme inferensi untuk pengujian aturan, yaitu penalaran maju (forward chaining) dan penalaran mundur (backward chaining).

1. Penalaran maju (Forward Chaining)

Dalam penalaran maju,aturan-aturan yang diuji satu demi satu dalam urutan tertentu. Urutan itu mungkin berupa urutan pemasukan aturan ke dalam basis aturan atau juga urutan lain yang ditentukan oleh pemakai. Saat tiap aturan diuji, sistem pakar akan mengevaluasi apakah kondisinya banar atau salah. Jika kondisinya benar, maka aturan itu disimpan kemudian aturan berikutnya diuji. Sebaliknya jika kondisi salah, aturan itu tidak disimpan dan aturan berikutnya diuji.

2. Penalaran mundur (Backward Chaining)

Merupakan penalaran dari sekumpulan hipotesis menuju fakta-fakta yang mendukung tersebut, jadi proses pelacakan berjalan mundur dimulai dengan menentukan kesimpulan yang akan dicari baru kemudian fakta-fakta pembangun kesimpulan.

\section{F. Metode Rule}

Representasi pengetahuan dengan rule (aturan) sering disebut juga dengan sistem produksisuatu rule terdiri dari 2 (dua) bagian yaitu:

1. Antocedent yaitu bagian yang mengekspresikan situasi atau premis (pengetahuan berawal $I F$ ).

2. Konsekuen yaitu bagian yang mengatakan suatu tindakan tertentu atau konlusi yang diterapkan jika situasi atau premis bernilai benar (pernyataan berawal THEN). Inferensi dengan rule (sebagaiman juga dengan logika dapat efektif, tetapi terdapat beberapa keterbatasan pada teknik-teknik tertentu.

\section{METODOLOGI PENELITIAN}

Proses penelitian ini akan dijelaskan dalam suatu kerangka kerja penelitian yang nantinya akan digunakan untuk mengambarkan langkah-langkah dalam penelitian. Adapun kerangka penelitian dijelaskan dengan gambar berikut. 
Jurnal Pseudocode, Volume V Nomor 1, Februari 2018, ISSN 2355-5920

www.ejournal.unib.ac.id/index.php/pseudocode

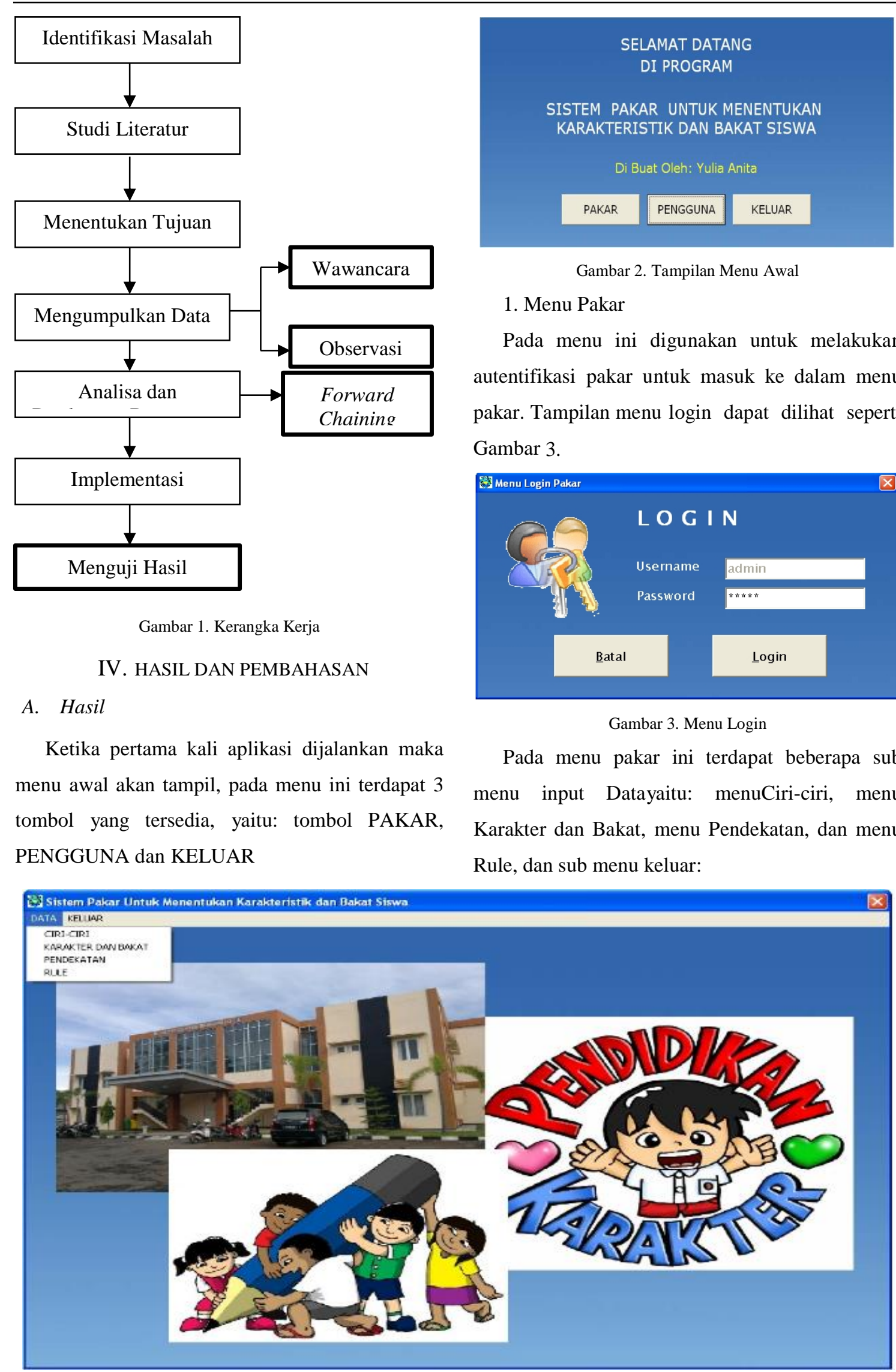

Gambar 4. Menu Pakar 
Jurnal Pseudocode, Volume V Nomor 1, Februari 2018, ISSN 2355-5920 www.ejournal.unib.ac.id/index.php/pseudocode

Menu ini digunakan untuk menambah, memperbaiki dan menghapus data ciri-ciri. Tampilan menu ini dapat dilihat pada Gambar 5.

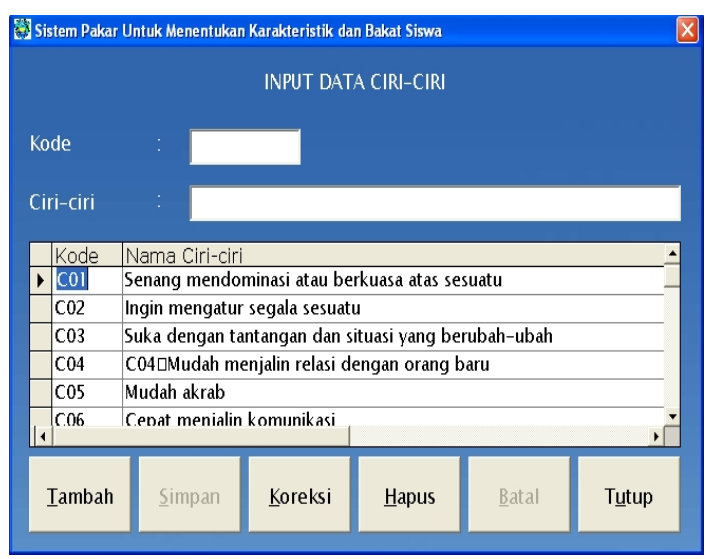

Gambar 5. Menu Ciri-Ciri

Menu ini digunakan untuk menambah, memperbaiki dan menghapus data karakter dan bakat. Tampilan menu ini dapat dilihat pada Gambar 6.

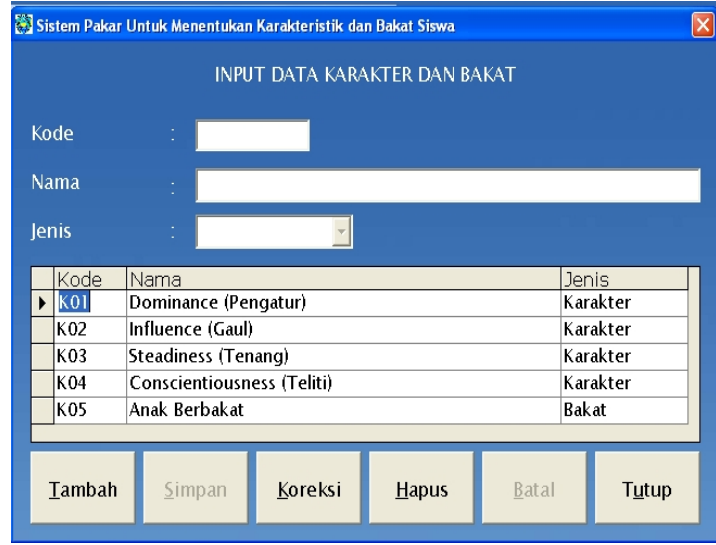

Gambar 6. Menu Karakter dan Bakat

Menu ini digunakan untuk menambah, memperbaiki dan menghapus data pendekatan. Tampilan menu ini dapat dilihat pada gambar 7.

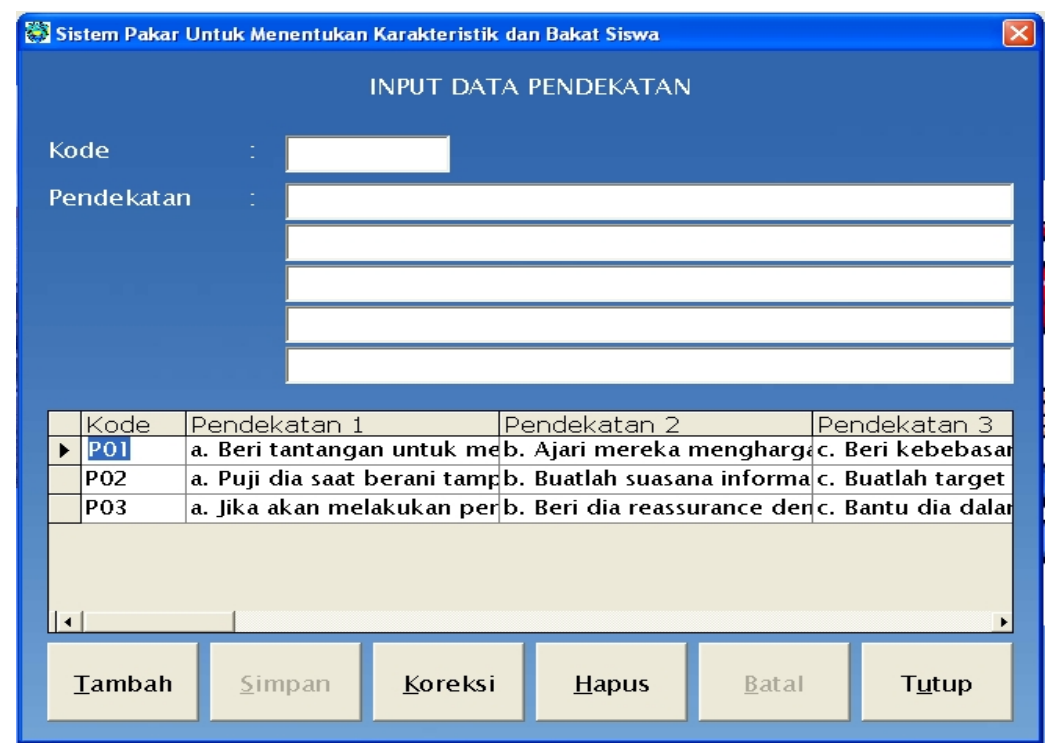

Gambar 7. Menu Pendekatan

Menu ini digunakan untuk menambah, memperbaiki dan menghapus data Rule.

Tampilan menu ini dapat dilihat pada Gambar 8. 
Jurnal Pseudocode, Volume V Nomor 1, Februari 2018, ISSN 2355-5920 www.ejournal.unib.ac.id/index.php/pseudocode

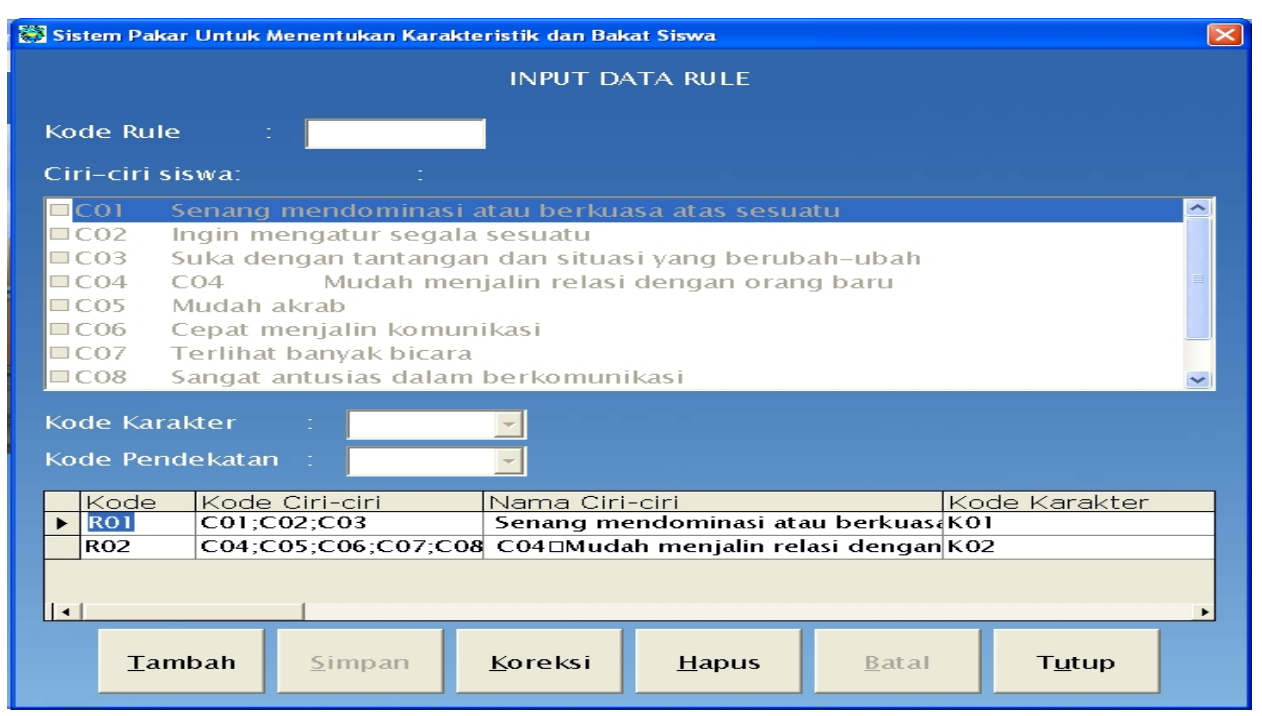

Gambar 8. Menu Rule

Menu ini digunakan untuk melakukan bakatsiswa. Tampilan menu ini dapat dilihat pada konsultasi yang berkaitan dengan karakteristik dan gambar 9.

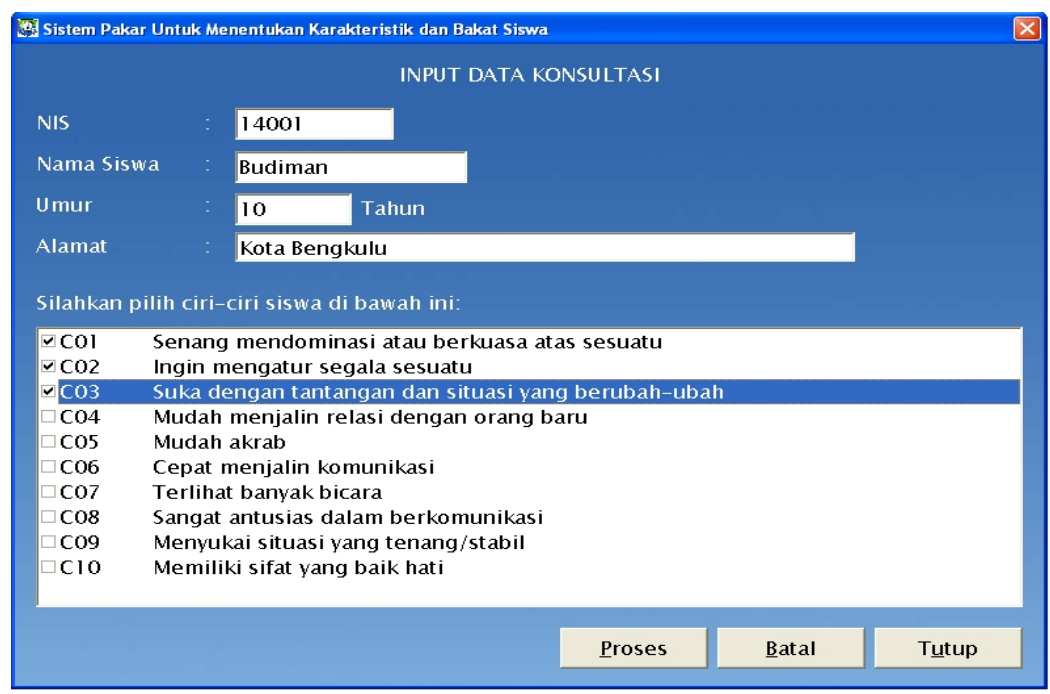

Gambar 9. Menu Konsultasi

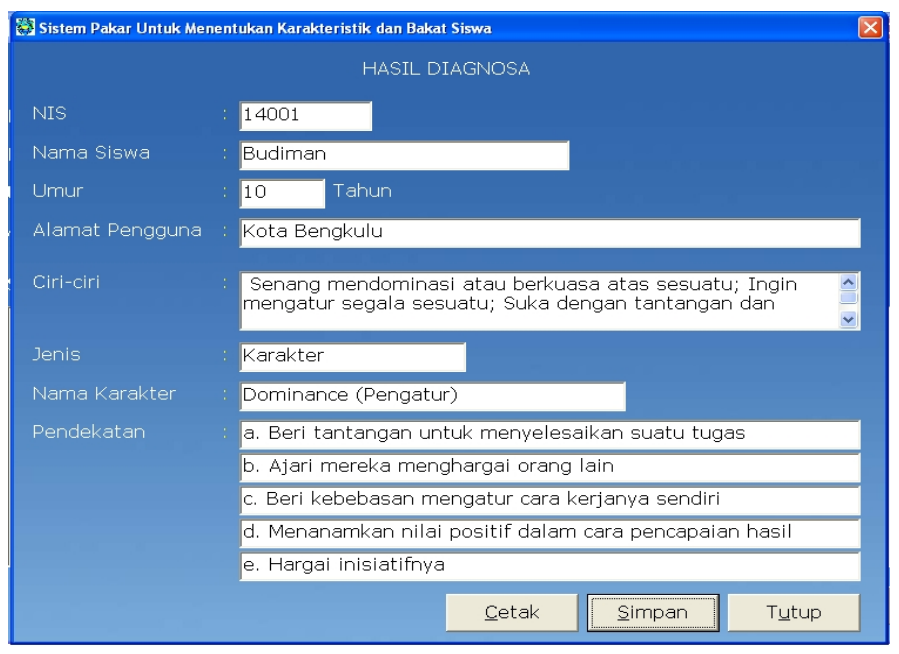


Jurnal Pseudocode, Volume V Nomor 1, Februari 2018, ISSN 2355-5920 www.ejournal.unib.ac.id/index.php/pseudocode

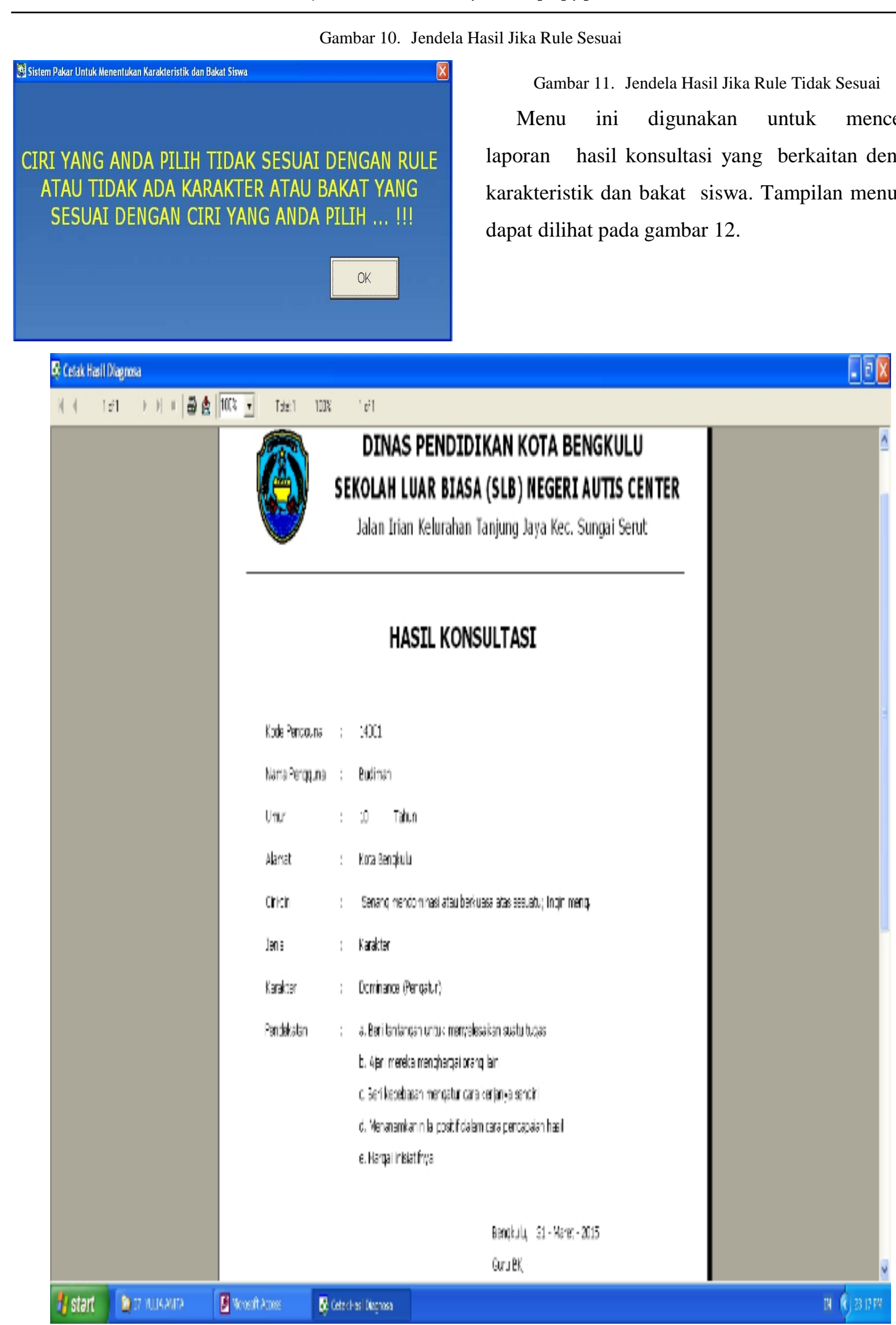

Gambar 12. Menu Laporan Hasil Konsultasi 


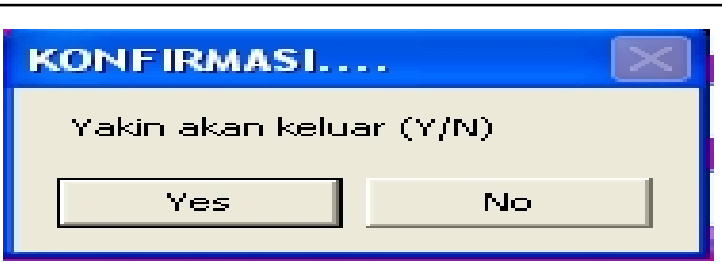

B. Hasil Pengujian

Gambar 13. Menu Kluar

Berdasarkan data hasil kuisioner yang
SLB diketahui presentase masing-masing jawaban dengan menggunakan rumus:

$\mathrm{N}=\mathrm{J} / \mathrm{R} * 100$

Keterangan:

$\mathrm{J}=$ Banyaknya jawaban tiap pertanyaan

$\mathrm{R}=$ Jumlah Responden

$\mathrm{N}=$ Nilai Persentase

disebarkan kepada 5 (lima) orang responden (guru

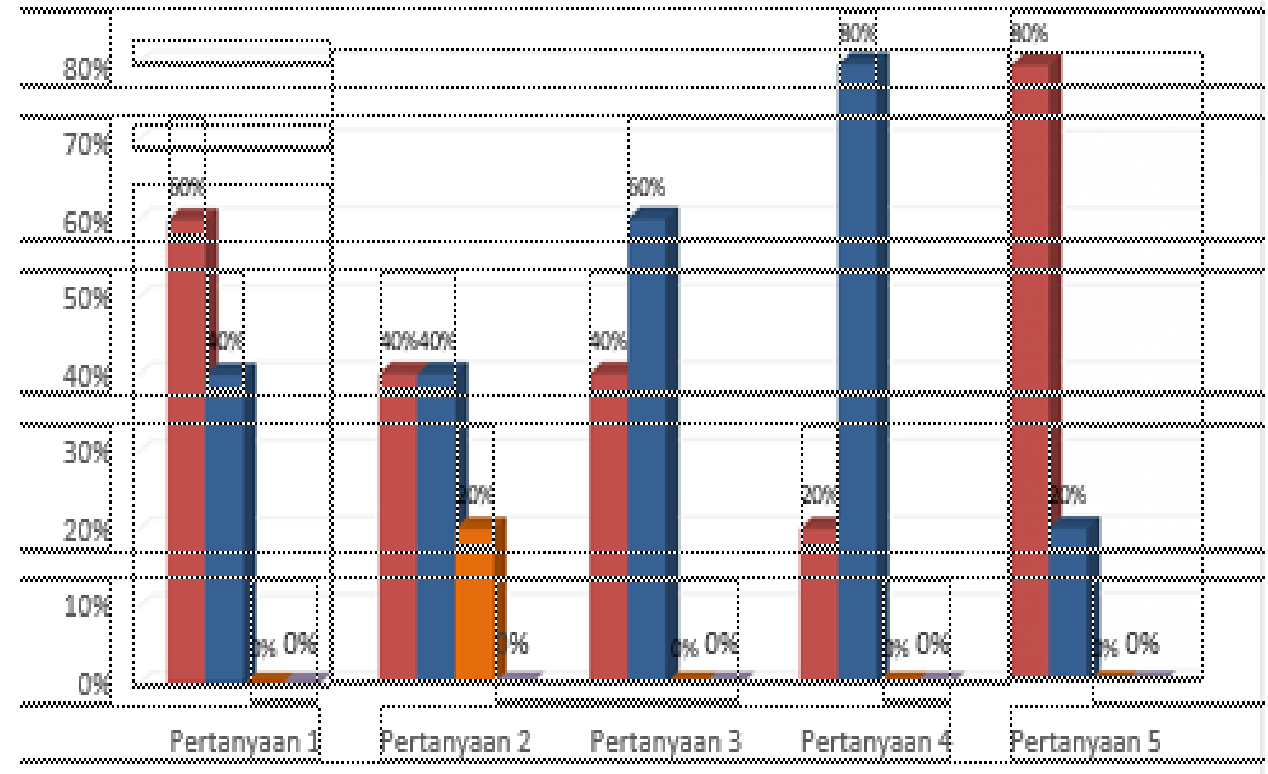

$\square \mathrm{A} \square \mathrm{B}\|\mathrm{C}\| \mathrm{D}$

Gambar 14. Grafik hasil pengujian

Dari grafik jawaban responden di atas didapat hasil bahwa dari 5 orang responden untuk pertanyaan satu memilih jawaban sangat baik dengan persentase $60 \%$ (3 orang), dan baik sebanyak $40 \%$ (2 orang), untuk pertanyaan dua memilih jawaban sangat baik sebanyak $40 \%$ (2 orang), baik sebanyak $40 \%$ (2 orang) dan cukup20\% (1 orang), untuk pertanyaan ketiga memilih sangat baik sebanyak $40 \%$ (2 orang), dan menarik 60\% (3 orang), untuk pertanyaan keempat memilih jawaban sangat baik $20 \%$ (1 orang), dan baik sebanyak $80 \%$ (4 orang), untuk pertanyaan kelima memilih jawaban sangat baik sebanyak $80 \%$ (4 orang), dan baik sebanyak 20\% (1 orang).
Berdasarkan persentase jawaban responden tersebut penulis mengambil kesimpulan bahwa aplikasi yang dibangun telah sesuai dengan rancangan yang diinginkan.

\section{PENUTUP}

Berdasarkan hasil penelitian dan pembahasan dapat ditarik kesimpulan sebagai berikut:

1. Sistem pakar untuk menentukan karakteristik dan bakat siswa ini dibuat dengan bahasa pemrograman Visual Basic 6, dan dapat dijalankan pada komputer dengan sistem operasi Microsoft Windows.

2. Sistem pakar yang telah dibuat menyediakan fasilitas bagi pakar yaitu untuk mengelola 
data dan mencetak laporan, sedangkan bagi pemakai disediakan fasilitas untuk melakukan konsultasi.

3. Dari hasil jawaban responden diketahui bahwa dari 5 orang responden untuk pertanyaan satu memilih jawabansangat baik dengan persentase $60 \%$ (3 orang), dan baik sebanyak $40 \%$ (2 orang), untuk pertanyaan dua memilih jawaban sangat baik sebanyak $40 \%$ (2 orang), baik sebanyak $40 \% \quad$ (2 orang) dan cukup20\% (1 orang), untuk pertanyaan ketiga memilih sangat baik sebanyak $40 \%$ (2 orang), dan menarik $60 \%$ (3 orang), untuk pertanyaan keempat memilih jawaban sangat baik 20\% (1 orang), dan baik sebanyak $80 \%$ (4 orang), untuk pertanyaan kelima memilih jawaban sangat baik sebanyak $80 \%$ (4 orang), dan baik sebanyak $20 \% \quad$ (1 orang). Berdasarkan persentase jawaban responden tersebut penulis mengambil kesimpulan bahwa aplikasi yang dibangun telah sesuai dengan rancangan yang diinginkan.

4. Sistem pakar dengan komputer ini mempunyai kelebihan dibanding kemampuan pakar manusia diantaranya: mudah digunakan, dapat di copy dalam jumlah banyak, tidak terbatas karena dapat digunakan diberbagai tempat, pengetahuan bersifat konsisten, dan kecepatan untuk memberi petunjuk konsisten dan lebih cepat

\section{REFERENSI}

[1] Andi. Pengembangan Sistem Pakar Menggunakan Visual Basic. Yogyakarta: CV. Andi Offset, 214 Halaman.

[2] Akbar, Reni, Prof. Dr dan Hawadi. 2010. Menguatkan Bakat Anak. Jakarta: Penerbit PT. Gramedia Widiasarana Indonesia, 137 Halaman.
[3] Sukmadinata, Nana Syaodih. 2005. Landasan Psikologi Proses Pendidikan. Bandung: Remaja Rosdakarya.

[4] Wibowo, Agus. 2012. Pendidikan KarakterUsia Dini (Strategi Membangun Karakter di Usia Emas). Yogyakarta: Penerbit: Pustaka Pelajar, 149 Halaman.

[5] --------. 2014. Faktor Pendukung Pengembangan Bakat dan Minat. http://minat- danbakat.blogspot.com/2014/01/faktor-pendukungpengembangan-bakat-dan.html. 